\title{
Contratos especiales
}

Javier Rodríguez Diez

Profesor de Derecho Romano

Pontificia Universidad Católica de Chile

TRANSACCIÓN SOBRE COSA AJENA: NULIDAD, INOPONIBILIDAD Y REIVINDICACIÓN. Corte Suprema, 10 de enero de 2018, rol N 16.657-2017.

\section{INTRODUCCIÓN}

La transacción tiene una reconocida peculiaridad si se la compara con otros contratos que pueden tener por objetivo la disposición sobre una cosa: la transacción sobre cosa ajena es nula. Así lo señalan, entre otros, los arts. 2447 y 2452 del $C C$. Ello supone una clara diferencia, por ejemplo, respecto a la compraventa (art. 1815 del $C C$ ), el aporte en sociedad (art. 2085 del $C C$ ) o la prenda (art. 2390 del CC), donde la validez del contrato queda, en principio, fuera de discusión si recae sobre cosa ajena, aunque deja subsistentes los derechos del dueño de la cosa en tanto no opere la prescripción adquisitiva.

Si bien estamos ante un régimen peculiar, no es claro qué implica para el verdadero dueño de la cosa. El propietario de un terreno se vio obligado a dilucidar este punto cuando dos de sus vecinos celebraron una transacción para demarcar sus predios, en tales términos que se superponían al suyo. Respecto de uno de sus vecinos, dedujo la acción reivindicatoria. Respecto del otro, en juicio separado, demandó la nulidad de la transacción con inoponibilidad en subsidio. En este último caso, el tribunal de primera instancia rechazó ambas acciones, mientras que la Corte de Apelaciones acogió la inoponibilidad de la transacción, decisión que fue revocada a su turno por la Corte Suprema, que acogió la nulidad.

Esta aparente exuberancia de remedios al alcance del dueño de la cosa evidencia la dificultad con la que la doctrina y jurisprudencia nacional enfrentan la nulidad de la transacción sobre cosa ajena. Particularmente espinoso es el problema de la relación entre nulidad e inoponibilidad, que aparecen como mutuamente excluyentes tanto en la forma en que el actor plantea su pretensión en el caso en comento como en el modo de razonar de los sentenciadores. Esta visión se encuentra profundamente arraigada en el modo de entender la relación entre nulidad e inoponibilidad en el Derecho chileno, tanto en términos generales como a propósito del contrato de transacción en 
particular ${ }^{1}$. El presente comentario busca simplificar el análisis de esta materia demostrando que, al menos en este caso concreto, la nulidad y la inoponibilidad no son remedios alternativos, sino que están llamados a articularse simultáneamente en el contexto de una acción de dominio.

\section{LA CUESTIÓN DEBATIDA}

En resumidas cuentas, la controversia que motivó la causa en comento se origina en la deficiente delimitación de tres predios en Chiloé, distribuidos de la siguiente forma: al norte, el fundo Ralihueno; al sur, Tablaruca; al centro, formando una delgada franja de terreno que separa los dos anteriores, Ayao. Según los planos de los dueños de Tablaruca, el fundo Ayao (su deslinde norte) sería una franja horizontal en el mapa, mientras que el dueño de Ralihueno consideraba que la distribución de Ayao (su deslinde sur) era más bien diagonal. Esta diferencia en los planos traía consigo una importante superposición de Ralihueno no solo sobre Ayao sino que, incluso, sobre Tablaruca, lo que llevó a los dueños de Ralihueno a efectuar actos posesorios sobre parte de Tablaruca. Frente a ello, los dueños de Tablaruca entablaron una acción reivindicato-ria.

Pendiente esta acción de dominio, Ralihueno celebró una transacción con Ayao a fin de establecer los deslindes entre ambos predios, acordando una 212 distribución diagonal acorde a los planos de Ralihueno. Esto implicaba, para los propietarios de Tablaruca, una superposición casi completa del fundo Ayao sobre su predio, por lo que demandaron en un nuevo juicio la nulidad de la transacción sobre esta franja de terreno, ya que habría recaído sobre cosa ajena, alegando en subsidio que dicha transacción les sería inoponible.

Si bien ambas causas fueron conocidas por un mismo tribunal, en primera instancia se alcanzaron decisiones contradictorias, aunque se acogió la reivindicatoria contra Ralihueno ${ }^{2}$, se rechazó tanto la nulidad como la inoponibilidad de la transacción entre Ralihueno y Ayao, por cuanto no constaría que la transacción hubiese recaído sobre cosa ajena ${ }^{3}$. Ambas causas fueron posteriormente conocidas en conjunto por la Corte de Apelaciones de Santiago, la cual mantuvo la contradicción de las decisiones de primera instancia, pero en sentido inverso: rechazó la acción reivindicatoria contra Ralihueno (por falta de individualización del objeto reclamado) ${ }^{4}$, mientras que acogió la acción de inoponibilidad de la transacción con $\mathrm{Ayao}^{5}$. En esta última decisión, los sentenciadores consideraron que no podía entenderse que la transacción

\footnotetext{
${ }^{1}$ Para una síntesis de las posturas antagónicas en la doctrina respecto a la procedencia de la nulidad y la inoponibilidad en la transacción sobre cosa ajena, véase VODANOvic (1993), pp. 94-96.

$25^{\circ}$ Juzgado Civil de Santiago, sentencia de 21 de octubre de 2015 en causa rol C-32.318-2011.

${ }^{3} 5^{\circ}$ Juzgado Civil de Santiago, sentencia de 28 de septiembre de 2015 en causa rol C-27.544-2012.

${ }^{4}$ Corte de Apelaciones de Santiago, sentencia de 1 de marzo de 2017 en causa N ${ }^{\circ}$ 1.151-2016.

${ }^{5}$ Corte de Apelaciones de Santiago, sentencia de $1^{\circ}$ de marzo de 2017 en causa $N^{\circ} 12.933$ 2015 .
} 
hubiera recaído sobre cosa ajena, ya que los deslindes de Ralihueno y Ayao se conformaban con su historia registral, aunque sí se comprobaba una superposición con los planos de Tablaruca, sin que sea el objeto de la acción de nulidad determinar la cabida exacta de cada predio. Por ello, negaron lugar a la nulidad, dejando a salvo la posibilidad de que Tablaruca recurriese a una acción de dominio al acoger la acción subsidiaria de inoponibilidad, fundándose en el efecto relativo de los contratos, los cuales, al obligar solo a quienes los suscriben, son esencialmente inoponibles a terceros (cons. $18^{\circ}-20^{\circ}$ ).

La Corte Suprema revocó ambas decisiones, fallando en favor de Tablaruca. Por una parte, se reconocieron todos los presupuestos de la acción reivindicatoria intentada contra Ralihueno, por lo que fue acogida ${ }^{6}$. Por otra parte, se constató que la transacción entre Ralihueno y Ayao recayó sobre un objeto ajeno a los demandados, por lo que acogió la acción de nulidad ${ }^{7}$. La Corte estimó infringido el art. 2452, que sanciona la transacción sobre cosa ajena con la nulidad, lo que tendría su fundamento en que la existencia de concesiones recíprocas es de la esencia del contrato de transacción (cons. $8^{\circ}-10^{\circ}$ ). A continuación, los sentenciadores analizan si se trata de un caso de nulidad absoluta o relativa, inclinándose por la primera alternativa, por subsumirse en un caso de falta de objeto. Ello, a su turno, permite que sea alegada por todo el que tenga interés en ello (conforme al art. 1683 del $C C$ ) como lo es en efecto el verdadero dueño de la cosa (cons. $11^{\circ}-12^{\circ}$ ). A juicio de la Corte, ello implica la improcedencia de la acción de inoponibilidad, por cuanto la nulidad absoluta sería una sanción especial para estos supuestos (cons. $4^{\circ}$ de la sentencia de reemplazo). De esta forma, para los sentenciadores la nulidad y la inoponibilidad serían sanciones mutuamente excluyentes, procediendo en este caso aplicar la nulidad por expresa disposición legal.

\section{Comentario}

\section{Nulidad de la transacción sobre cosa ajena}

A primera vista, podría pensarse que estamos ante un problema sencillo, ya que el $C C$ prescribe en diversas disposiciones que la transacción sobre cosa ajena es nula. Como bien señala la Corte Suprema, esta normativa tiene su origen en la importancia de las concesiones recíprocas para el contrato de transacción. Al moldear los contornos de este contrato, los juristas del ius commune reconocieron en las fuentes romanas que la transacción implicaba que ambas partes, necesariamente, debían dar algo o renunciar a algo ${ }^{8}$. Con el tiempo,

\footnotetext{
${ }^{6}$ Corte Suprema, sentencia de 10 de enero de 2018 en causa $\mathrm{N}^{\circ} 18.254-2017$.

${ }^{7}$ Corte Suprema, sentencia de 10 de enero de 2018 en causa $N^{\circ} 16.657-2017$.

${ }^{8}$ Particularmente influyente al efecto fue Codex Iustinianus 2, 4, 38: "La transacción no se verifica si nada es dado, retenido o prometido" (Transactio nullo dato vel retento seu promisso
} 
los juristas entendieron que esta reciprocidad exigía que quienes celebraran el contrato debían tener la facultad de disponer de sus bienes, declarándose, además, nula la transacción sobre cosa ajena ${ }^{9}$. Por otra parte, se elaboraron diversas hipótesis de consentimiento viciado relativas a la titularidad de los derechos en disputa ${ }^{10}$.

Estas doctrinas fueron recogidas -mediando el influjo del $C C$ francés- en nuestro $C C$, que establece en su art. 2447: "No puede transigir sino la persona capaz de disponer de los objetos comprendidos en la transacción”, mientras que el art. 2452 prescribe: "No vale la transacción sobre derechos ajenos (...)". Estas normas encuentran, además, un interesante complemento en la regulación especial de diversos vicios del consentimiento, como el error en la persona (art. 2456 inc. $1^{\circ}$ y $2^{\circ}$ del $C C$ ) y el error en la identidad del objeto (art. 2457 del $C C$ ). Particularmente, el art. 2459 del $C C$ regula el caso en que

"constare por títulos auténticos que una de las partes no tenía derecho alguno al objeto sobre que se ha transigido, y estos títulos al tiempo de la transacción eran desconocidos de la parte cuyos derechos favorecen",

estableciéndose como solución general que "la transacción podrá rescindirse". Encontramos así diversas normas que prescriben de forma alternativa la nulidad absoluta o relativa - "la declaración de nulidad o la rescisión" como 214 expresamente señala el art. 2460- en casos de ajenidad de la cosa objeto de la transacción ${ }^{11}$. No siendo el objetivo del presente comentario profundizar en el ámbito de aplicación de estas normas, bastará con señalar que ellas tienen efectos especialmente relevantes entre las partes del contrato, ya que permiten que el contratante afectado solicite la nulidad del contrato cuando se entere que su contraparte no tenía la facultad de enajenar ${ }^{12}$. Esto supone un evidente distanciamiento, por ejemplo, del régimen de la venta de cosa ajena, donde el comprador que se entere de haber recibido una cosa ajena al vendedor solo podrá exigir la responsabilidad contractual de esta último en caso de sufrir la evicción de la cosa. De esta forma, la nulidad de la transacción de cosa ajena

minime procedit). Sobre la delimitación conceptual de la transacción en época moderna, véase la reciente obra de PARINI Vincenti (2018).

${ }^{9}$ Véase, por ejemplo, VINNIO (1664), pp. 999-1004, por citar a un autor particularmente influyente en la aproximación de Andrés Bello al ius commune. En el mismo sentido DeLvincourT (1827), p. 336, autor citado reiteradamente en los proyectos del $C C$ en materia de transacción.

${ }^{10}$ Vinnio (1664), pp. 1043-1048; Delvincourt (1827), pp. 338-342. Sobre su tratamiento en el $C C$ francés véase Parini Vincenti (2018), pp. 121-134.

${ }^{11}$ Sobre las complicaciones que pueden surgir en este punto véase, por ejemplo, VoDanOVIC (1993), pp. 120-121, donde se aborda la sanción a la transacción celebrada en consideración a un título nulo.

${ }^{12}$ Cabe, en todo caso, apuntar que, de todas formas, en el caso en comento Ayao no persiguió la nulidad del contrato, sino que se adhirió a la postura de Ralihueno, lo que es característico de muchos juicios de dominio, donde el adquirente demandado suele preferir apoyarse en su predecesor en el dominio antes que aceptar las alegaciones del demandante. 
introduce, ante todo, diferencias relevantes en la forma en que las partes del contrato se relacionan entre sí. La gran pregunta es si esta sanción tiene efectos igualmente decisivos respecto del dueño de la cosa, y si acaso excluye la inoponibilidad del contrato.

\section{Inoponibilidad al dueño de la cosa, arts. 2456 y $2461 \mathrm{del} \mathrm{CC}$}

Para determinar la relación entre la nulidad y la inoponibilidad a propósito de la transacción sobre cosa ajena, es necesario, en primer lugar, hacer presente las limitaciones del concepto de 'inoponibilidad'. Se trata de una noción que se encuentra virtualmente ausente del $C C$ y que no es regulada sistemáticamente $^{13}$. Sin embargo, diversos autores a partir del siglo xx buscaron construir una sistemática de todos aquellos casos en los que un determinado acto jurídico no producía efectos respecto de terceros. Se reunieron así, bajo el paraguas de la "inoponibilidad", problemas tan diversos como la revocación de actos en perjuicio de los acreedores, el incumplimiento de formalidades de publicidad y la disposición sobre una cosa ajena ${ }^{14}$. Este esfuerzo sistemático vino aparejado con la afanosa búsqueda de ciertas reglas comunes que gobiernen estos distintos problemas y, en particular, dilucidar la naturaleza jurídica de la inoponibilidad. En este contexto, la doctrina y jurisprudencia nacional distinguen tajantemente entre nulidad e inoponibilidad, ya que la nulidad afectaría la validez misma del acto, mientras que la inoponibilidad supondría que el acto mantiene su validez, aunque no produce efectos respecto de determinados sujetos ${ }^{15}$. La diferencia entre ambas instituciones se acentuaría en la medida que la doctrina ha entendido que la inoponibilidad podría hacerse valer con una "acción de inoponibilidad" de contornos propios ${ }^{16}$.

La construcción de una teoría general de la inoponibilidad supone el evidente peligro de que esta noción general desplace las soluciones expresas del $C C$ en diversos puntos. Esto es precisamente lo que sucede en la causa en comento, que se encuadraría dentro de lo que la doctrina suele llamar "inoponibilidad por falta de concurrencia". Este concepto cubre una serie de casos en los que el titular de un derecho no otorgó su consentimiento para la celebración de un acto jurídico que lo afectaría negativamente, por lo que dicho acto jurídico desautorizado no puede afectarlo ${ }^{17}$. Sin embargo, no es necesario remitirse a

${ }^{13}$ Baltra (1935), p. 9; Romero (2011), p. 251; Vidal y Brantt (2015), pp. 617-618.

${ }^{14}$ Sobre el disímil carácter de los diversos supuestos de inoponibilidad, véase VIDAL y BRANTT (2015), p. 617.

${ }^{15}$ Baltra (1935), pp. 311-314; Abeliuk (2008), pp. 169-170; Romero (2011), pp. 253-255; Vidal y BrantT (2015), p.636. Cabe en todo caso recordar que, en ciertos casos, la inoponibilidad se refiere a los efectos de una declaración de nulidad, como indican BALTRA (1935), pp. 263-277 о AвELIUK (2008), pp. 173-174.

${ }^{16}$ Véase, por ejemplo, Romero (2011), pp. 251-264.

${ }^{17}$ Baltra (1935), pp. 239-252; Abeliuk (2008), pp. 171-172; Romero (2011), p. 252. 
una teoría general de la inoponibilidad para determinar qué sucede si alguien dispone de una cosa ajena sin consentimiento del dueño, ya que el art. 670 del $C C$ establece expresamente que en la tradición debe haber, por parte del tradente, la facultad de transferir el dominio, por lo que no se transferirá el dominio si no hay voluntad del tradente o su representante, como señala el art. 672. En otras palabras, hablar de una "inoponibilidad por falta de concurrencia" en este caso es una forma algo alambicada de decir que no se transfirió la propiedad, ya que alguien dispuso sobre una cosa ajena, dejando al dueño la posibilidad de recuperarla.

Fallando la transferencia de la propiedad por haber tenido lugar la tradición por un no propietario, ello no obsta, por otra parte, a que el contrato que le sirve de base -como lo es la transacción- sea en sí mismo nulo, lo que tiene un efecto adicional conforme a las reglas de la posesión, ya que el art. $704 \mathrm{~N}^{\circ} 3$ del $C C$ establece que se tratará de un título injusto" ${ }^{18}$. De esta forma, la "inoponibilidad por falta de concurrencia" no excluye la nulidad de título respectivo, lo que será relevante para efectos de determinar una posesión irregular que, a su vez, llevará a que los plazos de una eventual prescripción adquisitiva sean más prolongados (arts. 2507, 2508 y 2511 del $C$ C) ${ }^{19}$.

La convivencia de la "inoponibilidad por falta de concurrencia" con la nulidad se verifica en la regulación específica de la transacción. En este sentido, el art. 2456 inc. $3^{\circ}$ establece:

"si se transige con el poseedor aparente de un derecho, no puede alegarse esta transacción contra la persona a quien verdaderamente compete el derecho",

lo que pareciera no dejar dudas respecto a la "inoponibilidad" de la transacción sobre cosa ajena. De forma más general, el art. 2461 inc. $1^{\circ}$ prescribe: "la transacción no suerte efecto sino entre los contratantes", dejando fuera de discusión el efecto relativo de la transacción. Así, si bien el $C C$ establece la nulidad de la transacción sobre cosa ajena, no excluye en modo alguno su "inoponibilidad" respecto a terceros en general, ni respecto al dueño de la cosa en particular. Ello está, por lo demás, en línea con la doctrina del ius commune, que no tenía

18 "No es justo título (...) $3^{\circ} \mathrm{El}$ que adolece de un vicio de nulidad, como la enajenación que debiendo ser autorizada por un representante legal o por decreto judicial, no lo ha sido", art. 704 del $C C$.

${ }^{19}$ A propósito del título de posesión, cabe tener presente además que el art. 703 del $C C$ indica que las transacciones no forman nuevo título "en cuanto se limiten a reconocer o declarar derechos preexistentes", teniendo dicha calidad únicamente "en cuanto transfieran la propiedad de un objeto no disputado". Según Vodanovic (1993), p. 145, ello implica que el primer tipo de transacciones (como sería la del caso en comento) "no confieren título propio para justificar o fundar la prescripción del bien transigido. Subsiste el mismo título invocado para la transacción, con sus calidades o defectos; no se mejora ni empeora”. 
inconveniente en proclamar la nulidad de la transacción sobre cosa ajena y, a continuación, señalar que el contrato no podía perjudicar a terceros ${ }^{20}$.

La convivencia entre la nulidad y la "inoponibilidad" en el contexto de la transacción sobre cosa ajena se da también en otros sistemas jurídicos modernos. Por ejemplo, si bien el $C C$ italiano sanciona la nulidad de la transacción sobre cosa ajena, la doctrina y jurisprudencia han desarrollado un análisis de la "ineficacia subjetiva" de la transacción respecto de terceros, fundándose exclusivamente en las normas generales del efecto relativo de los contratos ${ }^{21}$. Sobre la base de este análisis se ha concluido, por citar un ejemplo particularmente pertinente, que en el caso en que dos dueños de predios vecinos lleguen a una transacción que superpone sus predios a los de un tercer vecino, dicho contrato (que invadió una esfera jurídica ajena) no producirá efectos respecto del tercero no involucrado ${ }^{22}$.

Pese a lo anterior, la doctrina y jurisprudencia nacional han analizado la transacción sobre cosa ajena partiendo del supuesto de la incompatibilidad entre nulidad e inoponibilidad. En la doctrina, por ejemplo, Ramón Meza Barros ha afirmado que la transacción sobre cosa ajena no es nula, sino inoponible al titular del derecho ${ }^{23}$, mientras que Antonio Vodanovic ha sostenido lo contrario $^{24}$. Por su parte, la Corte Suprema ha identificado un diverso ámbito de aplicación a las normas sobre nulidad e inoponibilidad en la transacción, haciendo aplicable la norma del art. 2546 inc. $3^{\circ}$ únicamente al caso en que el disponente ostente la posesión material o inscrita, lo que lo calificaría como "poseedor aparente" para efectos de este comentario. Para el resto de los casos -es decir, cuando la transacción fuese celebrada por quien no es poseedor aparente- se sancionaría la transacción con la nulidad ${ }^{25}$. Todas estas interpretaciones comparten un mismo defecto fundamental, que es asumir que la nulidad de la transacción sobre cosa ajena excluye su inoponibilidad.

\section{Acciones dominicales, nulidad e inoponibilidad}

Conforme a lo referido anteriormente, tanto la letra del $C C$ como sus antecedentes históricos dan cuenta que el verdadero dueño de la cosa no está obligado a elegir entre la nulidad y la "inoponibilidad", ya que no se trata de remedios mutuamente excluyentes, al menos en el supuesto en estudio. ¿Cómo debe

${ }^{20}$ Por ejemplo, Vinnio (1664), p. 1041 enuncia a modo de síntesis: "la transacción no perjudica o aprovecha a otros que aquellos que la celebraron" (Transactio non aliis nocet, aut prodest, quam qui eam interposuerunt). En el mismo sentido Delvincourt (1827), p. 337, comentando el $C C$ francés.

${ }^{21}$ Henke (2015), pp. 1029-1059; Parini Vincenti (2018), p. 153.

${ }^{22}$ Henke (2015), p. 1055.

${ }^{23}$ Meza Barros (2007), p. 176 ( $\left.\mathrm{N}^{\circ} 648\right)$.

${ }^{24}$ Vodanovic (1993), pp. 94-96, aunque más adelante (p. 106) admite una convivencia entre nulidad e inoponibilidad.

${ }^{25}$ Fisco de Chile contra Grellet Álvarez (1978). 
deducir el dueño, entonces, su pretensión? La respuesta debe encontrarse en la regulación que a este respecto contempla el $C C$ : si una de las partes de la transacción dispone de un objeto ajeno sin ser su dueño, la posición del verdadero dueño no se verá afectada ni por la tradición (arts. 670 y 672) ni por el contrato mismo de transacción (arts. 2456 y 2461), el cual será por lo demás nulo (arts. 2447 y 2452) por lo que dará lugar, a lo sumo, a una posesión irregular (art. $704 \mathrm{~N}^{\circ} 3$ ). En este contexto, las acciones dominicales se presentan como el medio inmediato para que el dueño de la cosa repela la intromisión que supone una transacción de terceros sobre su propiedad, debiendo analizar en el caso concreto si acaso ha perdido o no la posesión, recurriendo en el primer caso a la acción reivindicatoria y en el segundo a la acción meramente declarativa de dominio.

Esto no significa que la acción de nulidad como tal se encuentre fuera del alcance del dueño, aunque enfrenta importantes reparos prácticos. En primer lugar, obliga a deducir de forma indirecta una controversia dominical, existiendo la posibilidad de que el tribunal se sienta inclinado a dejar el análisis del problema del dominio para un juicio diverso, como resolvió la Corte de Apelaciones en el caso en comento. Más grave es que la legitimación activa del dueño puede no resultar acreditada, considerando que un tercero ajeno al contrato solo puede solicitar la nulidad absoluta (art. 1683 del CC), mientras que la transacción sobre cosa ajena podría eventualmente encuadrarse en una hipótesis de nulidad relativa (arts. 2456, 2457 y 2459 del CC). Finalmente, sobre la base de la artificial diferencia que ha planteado la jurisprudencia entre la nulidad e inoponibilidad de la transacción, atendiendo a si se tenía la "posesión aparente", el tribunal puede considerar que en un caso concreto procedía no la nulidad, sino la inoponibilidad.

Todavía más cuestionable resulta la procedencia autónoma de una "acción de inoponibilidad" en este caso. Como queda dicho, la llamada "inoponibilidad por falta de concurrencia" permite recurrir sin más a una acción dominical, por lo que el recurso a una acción de inoponibilidad resulta innecesariamente rebuscado. Así, si bien se suele afirmar que la venta de cosa ajena es "inoponible" al dueño, sería verdaderamente curioso que el dueño de la cosa vendida deje de lado las acciones dominicales para recurrir a una acción de inoponibilidad. Adicionalmente, existe una menor claridad respecto a diversos aspectos de la acción de inoponibilidad. Por ejemplo, la doctrina ha evidenciado la complejidad de declarar la inoponibilidad respecto de terceros adquirentes ${ }^{26}$, problema que no se plantea en materia de acciones dominicales, ya que el dueño podrá recuperar sus bienes de manos de quien los tenga. Asimismo, la acción de inoponibilidad no parece contemplar restituciones de ningún tipo en favor del demandante, por lo que no es de extrañar que en la causa en comento el actor no se conformó con la declaración de inoponibilidad de la Corte de Apelaciones, que lo dejó con las manos vacías. Por todo lo anterior, la acción

${ }^{26}$ Romero (2011), p. 260; Vidal y Brantt (2015), pp. 641-642. 
de inoponibilidad no parece llamada a cumplir una función relevante donde la pretensión del dueño pueda deducirse mediante una acción dominical e, incluso, la jurisprudencia ha declarado en ocasiones que la vía para hacer valer la "inoponibilidad por falta de concurrencia" es precisamente por medio de las acciones dominicales ${ }^{27}$.

\section{CONCLUSIONES}

A modo de conclusión, es posible afirmar que, frente a la transacción sobre cosa ajena, el verdadero dueño no se encuentra en la necesidad de elegir entre plantear la nulidad y la inoponibilidad para tutelar su derecho. El hecho de que la transacción de cosa ajena sea sancionada con la nulidad es especialmente relevante entre las partes del contrato, mientras que respecto del verdadero dueño de la cosa la principal consecuencia es que el adquirente tendrá, a lo sumo, una posesión irregular. Así, como en cualquier caso de disposición sobre una cosa por quien no tiene facultad de enajenar, el verdadero dueño no verá afectado su derecho (lo que el $C C$ reitera expresamente en materia de transacción) en tanto no transcurra el eventual plazo de prescripción (más extenso debido a la nulidad del título), disponiendo en el intertanto de acciones dominicales para hacer valer su derecho. La tajante contraposición entre nulidad e inoponibilidad no se verifica así ni en el supuesto de tradición de cosa ajena en general, ni en el supuesto particular de la transacción.

Lo dicho supone, además, una advertencia respecto al alcance que debe darse a cualquier intento de plantear una "teoría de la inoponibilidad", por cuanto esta noción cubre figuras disímiles en las que un sujeto puede desconocer un acto jurídico por diversas razones, sin que exista conexión histórica o dogmática entre dichos supuestos, ni mucho menos una mecánica común en su solución. En este sentido, forzar la aplicación de las soluciones comunes construidas en abstracto en torno al concepto de inoponibilidad tiene el riesgo de llevar a una hipertrofia de este concepto, que relegue al olvido la regulación del Código en materias específicas. Esto es precisamente lo que se verifica en la causa en comento, donde la aplicación de nociones generales relativas a la inoponibilidad, entendida como acción autónoma e incompatible con la nulidad, no solo resulta redundante sino que, incluso, distorsiona las soluciones del Código. En efecto, para el demandante (Tablaruca) la forma más apta de deducir su pretensión frente a Ayao era la misma que respecto de Ralihueno: ambos vecinos desconocían su dominio, por lo que en ambos casos debió deducir una acción dominical. Por su parte, no puede criticarse que la Corte Suprema acogiera la acción de nulidad, aunque sí resulta cuestionable que

${ }^{27}$ Comercial Amador Barrera y Compañía Limitada con Inmobiliaria e Inversiones Sol Naciente S.A. (2013), cons. $12^{\circ}$. Por su parte, CASTELLÓN (1991), p. 13 considera que ni siquiera es necesario recurrir a la inoponibilidad para resolver estas situaciones. 
declarase expresamente que la inoponibilidad es improcedente por el solo hecho de verificarse la nulidad del contrato.

\section{Bibliografía CitADA}

Abeliuk Manasevich, René (2008). Las obligaciones. $5^{\text {a }}$ ed. Santiago: Editorial Jurídica de Chile. Tomo I.

Baltra Cortés, Alberto (1935). Ensayo de una teoría general de los actos inoponibles. Santiago: [s.e.].

Castellón Munita, Juan Agustín (1991). "Nuevas consideraciones acerca de la teoría de la inoponibilidad”. Gaceta Jurídica. N $^{\circ} 129$. Santiago.

Delvincourt, Claude Étienne (1827). Cours de Code Civil. Bruselas: P.J. De Mat. Tomo 7.

Henke, Albert (2015). "I limiti soggettivi di eficacia della transazione". Rivista di diritto processuale. Año 70, $\mathrm{N}^{\circ}$ 4-5. Milán.

Meza Barros, Ramón (2007). Manual de Derecho Civil, De las fuentes de las obligaciones. $9^{\circ}$ ed. actualizada. Santiago: Editorial Jurídica de Chile. Tomo I.

Parini Vincenti, Sara (2018). Tra tutto e niente. Studi sulla transazione civile dal XVII secolo al Codice del 1865. Milán: Giuffrè Editore.

Romero Seguel, Alejandro (2011). "La acción para la declaración de inoponibilidad de un acto o contrato", en Alex ZÚÑIGA (ed.). Estudios de derecho privado: libro homenaje al jurista René Abeliuk Manasevich. Santiago: Editorial Jurídica de Chile.

Vidal Olivares, Álvaro y María Graciela Brantt Zumarán (2015). "La olvidada inoponibilidad. Una eficaz medida para la protección de intereses de terceros y la seguridad de tráfico", en Manuel BARRía et al. (eds.), Estudios de derecho privado en homenaje al profesor Ramón Domínguez Águila. Santiago: Thomson Reuters.

Vinnio, Arnoldo (1664). "Tractatus de transactionibus", in Arnold Vinnen. Jurisprudentiae contractae sive partitionum iuris civilis libri quattuor. Rotterdam: Arnold Leers.

Vodanovic, Antonio (1993). Contrato de transacción. Santiago: Editorial Jurídica ConoSur.

\section{Jurisprudencia citada}

Fisco de Chile contra Grellet Álvarez (1978): Corte Suprema, 29 de marzo de 1978 (casación en el fondo), cita Westlaw CL/JUR/9/1978.

Comercial Amador Barrera y Compañía Limitada con Inmobiliaria e Inversiones Sol Naciente S.A. (2013): Corte Suprema, 25 de junio de 2013 (casación en el fondo), rol N 6846-2012, cita Westlaw CL/JUR/1386/2013. 